\title{
Para a crítica da centralidade do trabalho: contribuição com base em Lukács e Postone
}

\author{
Towards the critique of the centrality of labor: a contribution \\ based on Lukács and Postone
}

\author{
Mario Duayer* \\ Paulo Henrique Furtado de Araújo**
}

\begin{abstract}
Resumo - $\mathrm{O}$ artigo procura contribuir para a autocrítica que a tradição marxista deve a si mesma. Baseia-se especialmente em Lukács e Postone para sustentar que a crítica das concepções correntes sobre trabalho, no interior da tradição, constitui um imperativo para tal autocrítica e, consequentemente, para a restauração da dimensão crítica da teoria marxiana. $\mathrm{O}$ argumento concentra-se na diferença entre trabalho como categoria fundante e central, e apresenta a seguinte estrutura: em primeiro lugar, oferece uma explanação sobre o caráter fundante do trabalho na gênese e desenvolvimento do ser social; em segundo, procura mostrar que a centralidade do trabalho é exclusiva do capitalismo e constitui a contradição básica desse sistema; em terceiro, defendendo que crítica de fato é crítica ontológica, sustenta que a crítica da economia política de Marx consiste na crítica do trabalho, ou da relação social armada pelo capital que unidimensionaliza os sujeitos como trabalhadores.

Palavras-chave: crítica ontológica; centralidade do trabalho; Marx; Lukács; Postone.
\end{abstract}

\begin{abstract}
The article is thought of as a contribution to the selfcriticism that the Marxian tradition owes itself. It is mainly based on the ideas of Lukács and Postone to argue that the critique of the usual conception of labor within the Marxian tradition is an unavoidable condition of that self-criticism. It focuses on the distinction between labor as a founding or central category and is structured as follows: firstly, it provides an explanation on the founding character of labor in the genesis and development of the social being; secondly, it attempts to show that the centrality of labor is exclusive to capitalism and constitutes the fundamental contradiction of this system; finally, assuming that true critique is an ontological critique, it argues that Marx's critique of the political economy is the critique of labor, or of the social relation made up by capital that unidimensionalizes people as workers.
\end{abstract}

Keywords: ontological critique; centrality of labor; Marx; Lukács; Postone.

\footnotetext{
* Professor visitante do Programa de Pós-Graduação em Serviço Social da Uerj. Correspondência: Est. Caetano Monteiro, 2201, casa 56. CEP 24.320-570, Niterói, RJ. E-mail:<mduayer@uol.com.br>

** Professor adjunto do Departamento de Economia da UFF. Correspondência: Rua Vitor Meireles, 32. CEP 20.950-

230, Riachuelo, Rio de Janeiro, RJ. E-mail:<phfurtadoa@gmail.com>
} 
[...] es menester mantenerse en la idea arduamente adquirida de que la crítica de las categorías económicas de Marx trasciende el dominio de la economía como disciplina especializada, es conveniente comprender de qué manera el análisis de la forma valor orientado sobre categorías filosóficas tiene como función la de superar las antinomias de esta economía especializada.

H.G. Backhaus

Tempos atrás, em plena atmosfera de intensa euforia, de júbilo pela celebração da nova (e, dessa vez, pretendidamente definitiva) morte de Marx, Derrida (1994) declara de forma sumária: "não há futuro sem Marx". Declaração tão mais surpreendente e, por que não dizer, paradoxal, porquanto vem de um pensador não marxista. Aijaz Ahmad (1994), marxista indiano, saúda a posição de Derrida (1994), importante numa época de afetado desdém por tudo que evoque Marx, mas não sem assinalar a diferença substantiva entre o esmaecido Marx derridiano e o Marx da crítica da sociedade governada pelo capital.

Muita coisa mudou desde então. O regozijo conservador se arrefeceu na mesma progressão do previsível fracasso das políticas preconizadas pelo tardo-liberalismo. Tendo em vista as tragédias que tem contribuído teórica, ideológica e politicamente para produzir em todos os cantos do globo, nem mesmo com sua notória desfaçatez teria como continuar prometendo um auspicioso mundo de "liberdade" e prosperidade. Nessas circunstâncias, o conservadorismo não comparece mais com a radiante e arrogante certeza de que restara como a única alternativa. Apesar disso, porém, conserva seu predomínio político-ideológico, agora sombrio, lúgubre, tal como o futuro que se pode prognosticar a se crer em sua postulação de que a história termina no presente.

No entanto, a opressiva sensação de epílogo que hoje se experimenta, a desalentadora percepção de que a humanidade não tem possibilidade de ir além da vida social regrada pelo capital - é preciso admitir não são obra exclusiva do conservadorismo. A aparente ausência de alternativa deve ser debitada também na conta do(s) tipo(s) de marxismo(s) prevalente(s) entre adeptos e, por extensão, adversários. Talvez se possa afirmar que nunca uma vitória deveu-se tão pouco à excelência do vitorioso quanto às debilidades do derrotado'. Daí a necessidade de crítica, no caso, de autocrítica para que a teoria marxiana possa reassumir sua condição de análise insuperável da estrutura e dinâmica da sociedade moderna, de suas contradições e de seus futuros possíveis.

'Já na década de 70 do século passado Lukács (2012, p. 299) adverte que, com o predomínio das correntes antiontológicas (neopositivismo e neokantismo), não muito tempo depois da morte de Marx a maioria dos seus seguidores encontrava-se sob a influência dessas correntes. Em consequência, segundo ele, o que existe de ortodoxia marxista consiste em "afirmações e inferências singulares de Marx, frequentemente mal compreendidas e sempre coaguladas em slogans radicais". 
O presente artigo procura contribuir para a autocrítica que nós, os herdeiros da tradição marxista, devemos antes de tudo a nós mesmos. Nesse particular, trazendo elementos já elaborados por autores marxistas, especialmente G. Lukács (2013) e M. Postone (2014), sustenta que a crítica das concepções correntes sobre trabalho no interior da tradição constitui um imperativo para a autocrítica e, consequentemente, para a restauração da dimensão crítica da teoria marxiana. Com esse objetivo, o argumento está centrado na diferença entre trabalho como categoria fundante e central, sendo exposto em três seções: na primeira, há uma explanação sintética sobre o caráter fundante do trabalho na gênese e desenvolvimento do ser social com base no capítulo sobre o trabalho da Ontologia de Lukács; na segunda, a partir das formulações de Postone, o propósito é o de explicar por que a centralidade do trabalho é exclusiva do capitalismo e constitui a contradição básica desse sistema; a terceira e última seção, apoiada na ideia de que crítica de fato é crítica ontológica, busca demonstrar que a crítica da economia política elaborada por Marx consiste na crítica do trabalho, ou da relação social armada pelo capital que unidimensionaliza os sujeitos como trabalhadores.

\section{O caráter fundante do trabalho na gênese e desenvolvimento do ser social}

Antes de tratar propriamente da análise do complexo do trabalho exposta por Lukács em sua Ontologia, é preciso enfatizar o sentido histórico dessa obra. ${ }^{2}$ Parece incontestável que, no fundo, o propósito foi dar conta da historicidade do ser social, sua historicidade específica, distinta das historicidades do inorgânico e do orgânico. Só compreendendo essa historicidade é possível determinar o papel do sujeito, da subjetividade na história, ou na autoconstituição do ser social. De fato, dependendo do tipo de historicidade o sujeito pode não ter nenhum papel, ou seja, não pode ser propriamente um sujeito. Esse seria o caso, como observa Lukács em inúmeras passagens, do materialismo mecanicista ao subentender que a sociedade dirige-se a um fim que se realiza de maneira inexorável independentemente da ação dos sujeitos.

Compreende-se, desse modo, que a Ontologia tenha sido concebida como prolegômenos de uma projetada ética (TERTULIAN, 1999; OLDRINI, 2013). Se a investigação da historicidade peculiar do ser social permite demonstrar que o sujeito tem nele um papel único em sua constituição e desenvolvimento, as questões éticas se impõem de imediato, já

\footnotetext{
${ }^{2}$ llustra essa orientação da obra seu comentário sobre as tentativas em apreender, em termos ontológicos, a historicidade do mundo social, que, para ele, podem ser vislumbradas em escritos de Aristóteles, Maquiavel e também de Vico, muito embora assinale que somente na ontologia marxiana "essas tendências alcançam uma forma filosoficamente madura e plenamente consciente." (LUKÁCS, 2012, p. 298).
} 
que a práxis como conduta social ativa, como agir teleológico, sempre pressupõe decisão entre alternativas, enfim, decisão entre valores. ${ }^{3}$

Contra as opiniões, portanto, que confundem o elevado grau de abstração da obra com uma atitude a-histórica, ${ }^{4}$ é absolutamente crucial ter presente que a categoria trabalho, em particular, é tratada em tal grau de abstração justamente para demonstrar essa historicidade específica, pois é pelo trabalho que o ser social, essa nova espécie de ser se autocria ao produzir as condições materiais de sua vida e, em razão disso, possui uma historicidade interna que as outras espécies não possuem. ${ }^{5}$

Para iluminar a particularidade do ser social, Lukács discute o problema do salto ontológico de uma forma de ser, sua gênese e diferenciação radical da forma de ser da qual se origina. O destaque aqui recai sobre o novo que surge e que, por isso, não pode ser derivado por indução ou dedução. Dado o salto ontológico, tem-se um todo desenvolvido com constituição própria para cuja compreensão não é possível recorrer a esses tipos de inferência. Ao contrário, é preciso partir do todo desenvolvido e, por meio de procedimentos abstrativos, obter os elementos constitutivos que permitam a sua reconstrução ideal. Claro está, como observa Lukács referindo-se às indicações de Marx, que essa reconstrução não pode partir de qualquer abstração. Como toda ciência tem de totalizar e, ao fazê-lo, resulta empiricamente plausível, o caminho do abstrato ao concreto mencionado por Marx deve se referir não apenas à totalização propriamente dita, mas ao modo de totalizar e ao ponto de partida, pois

considerado isoladamente, qualquer fenômeno pode - uma vez transformado em 'elemento' por meio da abstração - ser tomado como ponto de partida; só que um tal caminho não levaria jamais à compreensão da totalidade. O ponto de partida, ao contrário, deve ser uma categoria objetivamente central no plano ontológico. (LUKÁCS, 2012, p. 312).

Precisamente por esse motivo, ao justificar porque, do ponto de vista metodológico, para expor ontologicamente a constituição do ser social deve-se iniciar pelo trabalho, Lukács faz menção à conhecida passagem de Marx, em $O$ capital, sobre a diferença entre o trabalho e as operações realizadas por abelhas e aranhas para sublinhar que ali se enuncia uma categoria central do trabalho, pois nele sucede um pôr teleológico no âmbito

\footnotetext{
3Parafraseando Thompson (1978), como "ser moral e racional", o ser humano sempre tem de decidir entre alternativas e, portanto, entre valores. Sobre a relevância desse trabalho de Thompson para a compreensão da historicidade do ser social, ver Duayer (2006).

${ }^{4} \mathrm{~A}$ identidade entre ontologia e a-historicismo é confusão comum e muito antiga. Perry Anderson oferece ilustração notável desse equívoco, na medida em que, do alto de sua autoridade, sequer considera necessário justificar sua redução de ontologia a postulações metafísicas. De fato, em sua crítica à análise de Thompson sobre as relações de W. Morris com o marxismo, Anderson sustenta que o erro de Thompson consiste em substituir "uma explicação histórica por uma ontológica". (ANDERSON, 1980, p. 160 grifo no original)

5" [...] o trabalho no sentido de simples produtor de valores de uso é o início genético do devir homem do homem." (LUKÁCS, 2013, p. 156).
} 
do ser material que dá origem a uma nova objetividade. Característica que confere ao trabalho a posição de destaque na gênese e no processo de desenvolvimento do ser social e o seu exclusivo caráter intermediário.

Ao criar novas formas de objetividade, o trabalho, como metabolismo do ser humano, da sociedade com a natureza, marca a transformação no ser humano que trabalha do meramente biológico no ser social. (LUKÁCS, 2013, p. 44 e 47) Essa nova forma de ser emerge do orgânico e dele se diferencia porque, mediante o trabalho, põe e repõe, cria as próprias condições de reprodução.

Por ser agir teleológico, atividade que põe finalidades e as realiza materialmente, ou inscreve na realidade algo que as causalidades naturais não produziriam por si sós, o trabalho cria as condições materiais da vida. Em outras palavras, sem qualquer postulação, ao se iniciar pelo trabalho, por essa atividade específica do humano, é possível inferir que o ser social se autocria ou, como salienta Lukács, que o típico no ser social é a reprodução ampliada, resultado da dialética entre necessidade e sua satisfação.

O pôr de finalidade inverte a determinação biológica prevalente no orgânico, processo causal em que é o passado que determina o presente. As transformações nos processos de reprodução filo e ontogenético são provocadas por alterações ocorridas no meio ambiente, no passado portanto. O pôr de finalidade muda tal determinação na medida em que é o futuro - o mundo tal como figurado na finalidade - que determina a ação. Nesse caso, portanto, há uma inversão no andamento, pois no ser social o futuro determina o presente (LUKÁCS, 2013: 98).

Não seria possível, claro, a partir dessas considerações iniciais, cobrir toda a riqueza do capítulo da Ontologia aqui tratado. As observações acima importam sobretudo para chamar a atenção para a característica central do ser social pressuposta no trabalho: em lugar de se adaptar ao mundo tal como ele existe, o ser social cria o seu próprio mundo exterior e, ao fazê-lo, também se recria continuamente, desenvolve suas potencialidades. Talvez se possa afirmar que o sentido maior da Ontologia consista em procurar capturar o desenvolvimento do ser social, sua diferenciação e estratificação crescentes, conformando um complexo de complexos, que tem sua gênese no trabalho, tal como explica o autor:

[trata-se de apreender as] formas fenomênicas das condutas de vida especificamente humanas que, embora através de amplas mediações, emergem do trabalho e que, por isso, devem ser concebidas ontológico-geneticamente a partir dele. ${ }^{6}$ (LUKÁCS, 2013, p. 126).

Empregando esse método ontológico-genético, a análise do trabaIho realizada na Ontologia oferece inúmeras ilustrações da gênese de novas

\footnotetext{
${ }^{6}$ Tertulian $(2009$, p. 376) assim se manifesta sobre essa conexão: "Pode-se definir seu método como 'ontológicogenético', na medida em que procura mostrar a estratificação progressiva das atividades do sujeito".
} 
esferas, que marca a crescente complexificação e estratificação resultantes do desenvolvimento do ser social. Na impossibilidade de comentar todos os casos examinados pelo autor, a exposição da gênese da ciência, tal como aparece na Ontologia, serve para mostrar o "método ontológico-genético" em operação, por assim dizer. ${ }^{7}$ Para sintetizar o procedimento de Lukács, basta observar que ele parte dos dois componentes do trabalho já analisados por Aristóteles: o pensar, em que um fim é posto e se buscam os meios de sua realização; e o produzir, em que o fim anteposto devém real. A formulação de Aristóteles é enriquecida pela incorporação da decomposição analítica do primeiro ato proposta por Hartmann, a saber, o pôr do fim e a investigação dos meios.

A contribuição de Hartmann, de acordo com Lukács, não altera a essência ontológica da proposta de Aristóteles, além de torná-la mais concreta e esclarecedora. Tal essência consiste em que um projeto ideal é materialmente realizado, ou em que a finalidade pensada transforma a realidade material. O resultado é a inserção na realidade de algo material que é qualitativa e radicalmente novo, pois não poderia resultar da operação normal dos processos causais da natureza.

O primeiro ato, o pôr do fim, é determinado por necessidades sociais e tem o propósito de satisfazê-las. O segundo ato, a investigação dos meios, constitui o pressuposto absolutamente necessário para alcançar esse objetivo, porque o conhecimento correto, mais detalhado possível das relações e das propriedades dos objetos envolvidos no pôr do fim é condição imprescindível para que, no trabalho, se possa converter causalidades naturais em causalidades postas, que, no final do processo, resultam no produto, tal como ideado no pôr do fim. Nisso consiste o agir teleológico: sem mudar a essência das causalidades naturais, deve "canalizálas" ou dispô-las em tal ordem de modo que operem em função da finalidade, transformá-las em causalidades postas.

Apesar de constituírem uma unidade, as duas atividades são substancialmente heterogêneas, conforme salienta Lukács. De fato, enquanto o pôr do fim determina o modo de se dirigir à realidade, de apropriá-la mentalmente, a investigação dos meios, ao contrário, impõe a observação estrita das propriedades e conexões dos objetos e materiais relacionados com realização do fim. Em outros termos, enquanto o pôr do fim implica a antropomorfização da realidade, a investigação dos fins é inerentemente desantropomorfizadora. Tal heterogeneidade mal pode ser vislumbrada, é claro, nas formas de trabalho originárias e elementares, condicionadas que são pelos fins particulares de cada trabalho concreto. No entanto, agrega Lukács, o conhecimento adquirido em um trabalho específico pode ser utilizado em outro, em circunstâncias em tudo distintas do primeiro.

\footnotetext{
${ }_{7}$ Para evitar multiplicação excessiva de referências, vale registrar que explanação que se segue está baseada no argumento desenvolvido por Lukács (2013) nas páginas 52 e ss.
} 
Não seria o caso, aqui, de reproduzir todos os pressupostos concretos implicados na existência do trabalho, como característica específica do ser social, que Lukács infere dessa sua consideração abstrativante: conhecimento, consciência (não mais epifenomênica), linguagem, pensamento conceitual, separação sujeito-objeto, entre outros. O importante nesse momento é reconhecer que o trabalho pressupõe não somente o conhecimento da realidade, qualquer que seja o grau, mas também envolve a sua generalização, pois disso se trata quando os conhecimentos adquiridos em processos de trabalhos específicos são fixados e utilizados em contextos diferentes.

Lukács situa nessa propriedade intrínseca do trabalho - a generalização dos conhecimentos adquiridos - a gênese da ciência. Evidentemente, o autor não identifica tal generalização, em geral inconsciente, com a ciência, mas apenas mostra que ali, no trabalho e no conhecimento da realidade que ele implica, está radicada a sua gênese. Em adição, sublinha que a generalização presente no trabalho expressa a autonomização dos conhecimentos em relação aos fins que Ihes deram origem, ou explicita a já referida heterogeneidade entre pôr do fim e investigação dos meios.

Das necessidades surgidas da complexificação dos processos de trabalho, da crescente divisão do trabalho e socialização do processo de produção, observa Lukács, a investigação dos meios termina por se constituir como esfera autônoma, como ciência. A heterogeneidade agora passa a ser entre ciência e técnica.

A ciência, como esfera apenas relativamente autônoma, também responde às necessidades sociais. Todavia, sua função social é distinta da técnica, cujo propósito é o de contribuir para a realização de finalidades imediatas. A ciência, ao contrário da técnica, embora seja seu pressuposto, sua condição, tem por objetivo capturar o mundo tal como ele é em si mesmo. A sua função social é a busca da verdade, não a verdade absoluta, é óbvio, mas o conhecimento mais adequado possível das coisas tais como elas são em si mesmas, da realidade. Nesse sentido, pode-se dizer que a ciência tem uma orientação propriamente ontológica - vai ao ser das coisas, desantropomorfizando.

Tais considerações permitem mostrar, portanto, a emergência da ciência como esfera autônoma constitutiva do ser social, cuja gênese é possível situar no trabalho, e que serve de ilustração exemplar da criação de novas esferas e complexos envolvida no desenvolvimento do ser social. Para formulá-lo de maneira mais direta: o desenvolvimento do ser social se caracteriza por uma crescente complexificação e diferenciação, cujo pressuposto é o aumento da produtividade do trabalho social. De fato, o tempo exigido para a práxis social nos novos complexos e esferas unicamente pode ser criado pelo incremento da produtividade. Por conseguinte, se o desenvolvimento do ser social depende da produtividade do trabalho, podese afirmar que tudo o que somos e podemos ser depende do trabalho (e de sua produtividade). 
Nesse sentido, precisamente o trabalho é fundante, ou, caso se queira, é central na gênese e desenvolvimento do ser social. Nas palavras de Lukács (2013, p. 117):

[a] constituição ontológica da esfera econômica [do trabalho] ilumina a sua conexão com os outros âmbitos da práxis humana. Como já vimos muitas vezes em outros contextos, à economia cabe a função ontologicamente primária, fundante. E, apesar de já ter dito também isto muitas vezes, vale a pena sublinhá-lo mais uma vez: em tal prioridade ontológica não está contida nenhuma hierarquia de valor. Com isso realçamos apenas uma situação ontológica: uma determinada forma do ser é a insuprimível base ontológica de outra, e a relação não pode ser nem inversa nem recíproca. Tal constatação é em si totalmente livre de valor. (grifo nosso).

No entanto, não é difícil perceber que o trabalho gera uma dinâmica que o torna um dos muitos componentes do complexo de complexos aos quais por necessidade, imediata ou mediatamente, dá origem. Por conseguinte, apesar de permanecer fundante, com o desenvolvimento do ser social o complexo do trabalho passa a representar uma fração declinante da totalidade.

Vai-se ver na próxima seção que na sociedade capitalista o trabaIho, embora fundante, mas tendencialmente decrescente em relação aos outros complexos e às correspondentes práticas humano-sociais, também é central. Portanto, a contradição básica dessa sociedade reside precisamente nessa centralidade, que é sempre recomposta pela acumulação de capital a despeito do crescimento vertiginoso da produtividade do trabalho social tornar o trabalho, como um complexo dentre os múltiplos complexos que compõem o ser social, proporcionalmente cada vez menos relevante. Há uma contradição absurda entre essa irrelevância crescente do trabalho e sua centralidade nessa forma de sociedade.

Por essa razão, pode-se pôr em dúvida a interpretação corrente na tradição marxista segundo a qual o trabalho é a categoria central na crítica de Marx. Noção que se manifesta numa espécie de apologia, apoteose do trabalho, ternura pelo trabalho. Não é um acaso que Marx tenha sido associado ao trabalhismo, não só aqui mas internacionalmente, quando, na verdade, sua análise da formação social governada pelo capital não apoia de forma alguma tal inferência. Muito pelo contrário, como será visto na próxima seção, a crítica de Marx é a rigor crítica da centralidade do trabalho, crítica da sociedade em que o trabalho, por ser categoria mediadora social, é central. 


\section{Postone e a centralidade do trabalho no capitalismo ${ }^{8}$}

Postone se propõe a construir uma leitura específica e inovadora dos últimos textos de Marx. Nessa leitura, as categorias básicas de Marx não são tomadas apenas como a manifestação de um modo específico de exploração, mas, ao contrário, expressam uma dinâmica própria ao modo de vida constitutivo da sociedade capitalista, caracterizada por formas de dominação quase-objetivas, abstratas.

Desse modo, categorias como trabalho e capital são a expressão e elementos constitutivos de uma dinâmica histórica específica socialmente construída. Posta no mundo dos homens, tal dinâmica traz a possibilidade objetiva de sua superação e, no mesmo movimento, bloqueia a possibilidade de emancipação humana na entificação de uma sociabilidade póscapitalista.

A categoria valor é o fundamento desta dinâmica. O valor é a forma específica que a riqueza assume no capitalismo e, simultaneamente, uma forma de mediação social singular. A partir de tal estrutura interpretativa, Postone elabora um aparato teórico destinado a capturar os elementos centrais do capitalismo comuns a todas as épocas de sua evolução histórica.

No entanto, Postone não sustenta com isso que o Marx maduro constrói uma teoria com validade trans-histórica ou "ontológica", ${ }^{9}$ pois sua teoria tem uma perspectiva intrínseca ao objeto estudado, de tal maneira que suas categorias são historicamente específicas, ou seja, exclusivas do modo de produção capitalista. Afirmar a validade trans-histórica da teoria marxiana tem como desdobramento lógico, de acordo com o autor, a identificação de uma dialética intrínseca à história humana ou do trabalho como elemento central na constituição da vida social - para Postone noções patentemente trans-históricas.

Partindo da análise de Marx sobre a mercadoria, Postone destaca que ali já se demonstra o duplo caráter do trabalho no capitalismo: concreto e abstrato. A sua crítica se concentra nas interpretações usuais do trabalho abstrato como trabalho concreto tomado em abstrato. No caso do trabalho concreto, sua análise não apresenta qualquer novidade na medida em que afirma sua presença em toda e qualquer sociedade humana e faz a mediação entre o homem e natureza. O trabalho abstrato, todavia, não pode ser entendido como o trabalho concreto abstraído de suas particularidades concretas. Para o autor, ao contrário, trata-se de um tipo categorial diferente, não consistindo em uma categoria fisiológica, mas social e inerente à sociabilidade posta pela lógica do capital (POSTONE, 2014).

\footnotetext{
${ }^{8}$ Esse item é uma releitura da primeira parte do artigo "Superação do capitalismo a partir da lógica humano-societária do trabalho? Postone, Lukács e Chasin se encontram." (ARAỦJO, 2011).

${ }^{9}$ Postone ainda que elabore uma crítica ontológica, toma ontológico e trans-histórico como sinônimos e parece confundir ambos com uma atitude a-histórica. Sobre esse equívoco muito difundido, ver nota 9.
} 
Postone reafirma a concepção de que o trabalho no capitalismo é a substância do valor, mas agrega que ele possui uma função única nessa sociedade, a saber, a função exclusiva de mediação social, constituindo uma forma abstrata de interdependência social. Em virtude disso, possui uma dimensão social que não é intrínseca à atividade do trabalho em si. Fato que, para Postone, corrobora a sua avaliação de que, para Marx, o trabalho no capitalismo não é trans-histórico, mas constitui a atividade mediadora social historicamente determinada que põe como objetivações a mercadoria e o capital - ao mesmo tempo produtos de trabalho concreto e formas de mediação social.

Para Postone (2004, p. 59; 2014, p. 174s.) a teoria do valortrabalho de Marx não é uma teoria do valor-trabalho da riqueza, nem tampouco uma teoria que tem por centro a explicação do funcionamento do mercado e da exploração do homem pelo homem. Como o trabalho sempre foi a fonte social da riqueza em qualquer tempo e lugar, parece evidente, conclui ele, que Marx analisa o valor como forma historicamente específica da riqueza que, ao mesmo tempo, também é uma forma de mediação social. Por isso, Marx diferencia valor de riqueza material, sendo a riqueza material mensurada pela quantidade física de valores de uso produzidos e explicada por fatores associados ao trabalho concreto no processo de produção: conhecimento, organização social, condições sociais etc. $\mathrm{O}$ valor constituído pelo trabalho gasto na produção, por sua vez, é mensurado pelo tempo despendido e se apresenta como a forma de riqueza dominante no capitalismo.

Como capital é valor em expansão, valor que se valoriza, e valor é o trabalho humano abstrato que só pode ser quantificado pelo tempo gasto no próprio processo de trabalho, segue-se que a dominação posta pelo capital é do tempo sobre os homens, ainda que intermediada pelas coisas que os homens produzem. Em suma, o valor é uma forma automediadora da riqueza, que põe e bloqueia a possibilidade histórica de sua própria superação por uma sociabilidade baseada na produção consciente de riqueza material. (POSTONE, 2004, p. 59; 2014, p. 176-177)

Portanto, o que caracterizaria o capitalismo, segundo Postone, é a presença de um tipo de mediação social abstrata e historicamente específica que é posta pelo trabalho. Mediação esta constituída por determinadas formas de prática social que se tornam quase-independentes das pessoas envolvidas na entificação dessas práticas.

Tal referencial teórico de acordo com Postone (2004, p. 59-60; 2014 , p. 18s, p. 40s, p. 186s, p. 249s.) mostra que estamos diante de uma forma historicamente nova de dominação social. Forma que não pode ser compreendida exclusivamente em termos de dominação de classe, pois é impessoal e tem imperativo e constrangimentos estruturais específicos. Ela não tem um locus determinado e parece não ser social, apesar de ser constituída por formas específicas de práticas sociais. 
A mesma estrutura teórica permite ao autor (2004, p. 60; 2014, p. 224-225s.) sustentar que o capitalismo possui uma dinâmica peculiar caracterizada por um aumento inexorável da produtividade do trabalho, com consequente redução do valor por unidade de mercadoria. Tal tendência é orientada pela dimensão temporal do valor.

A dominação das pessoas pelo tempo, como já observado, é a forma abstrata e historicamente específica de dominação social intrínseca às formas fundamentais de mediação social na sociedade capitalista. Tal dominação abstrata, por sua vez, está associada a uma forma específica e abstrata de temporalidade - o tempo abstrato newtoniano (tempo lógico). Como valor e mais-valor são trabalho humano abstrato, portanto, indiferenciáveis entre si, a verificação da ampliação do valor, da produção de valor a mais, da valorização, só pode ser feita através da quantificação do tempo gasto no processo de trabalho produtor das mercadorias. Por esse motivo, a temporalidade abstrata encontra-se necessariamente associada à produção de valor e mais-valor, e, por conseguinte, ao aumento da força produtiva do trabalho e à extração de mais valor relativo como momento decisivo para o processo de acumulação de capital.

Todo esse movimento ocorre no interior dessa temporalidade abstrata. Formulando em outros termos, o valor que é mensurado pelo tempo de trabalho socialmente necessário (em média) para produzir a mercadoria é a própria expressão da transformação do tempo concreto em tempo abstrato no capitalismo. Esse valor se põe como uma norma temporal objetiva e impessoal autoimposta aos seres humanos, e que "se reconstitui continuamente ao longo da história. Os produtores não são só obrigados a produzir de acordo com uma norma temporal abstrata, mas devem fazê-lo de forma historicamente adequada: eles são obrigados a 'se manterem atualizados'." (POSTONE, 2014, p. 347).

O valor, ou seja, o tempo de trabalho, é a própria riqueza no capitalismo e o material do qual são feitas as relações sociais (POSTONE, 2014 , p. 348). Trata-se de um metabolismo criado pelo trabalho dos seres humanos e que domina os produtores e os obriga a continuar trabalhando, garantido a manutenção dessa dominação.

Postone (2004, p. 60-61; 2014, p. 92s.) vincula diretamente a descrição de Marx dessa dinâmica do capital e a correlata dominação abstrata ao movimento do Geist (Espírito),tal como exposto por Hegel na Fenomenologia. Em sua opinião, em $O$ capital, Marx tenta explicar social e historicamente o que Hegel apreende com o conceito de Geist (POSTONE, 2014). Para ele, a linguagem de Marx, ao tratar o capital como movimento, é similar à de Hegel para descrever o Espírito como substância automovente, que é sujeito do seu próprio processo. Dessa forma, Postone sugere que Marx permite entender que o sujeito histórico deve de fato existir no capitalismo, não como espírito hegeliano, mas como valor. 
Postone $(2004$, p. $60-61 ; 2014$, p. 92 s. $)$ procura articular a descoberta de um espírito hegeliano na análise do Marx "maduro" à teoria da alienação apresentada por Marx em seus primeiros trabalhos. De acordo com ele, na formulação de Marx o desdobramento da lógica dialética do capital é uma expressão real das relações sociais alienadas, que, embora constituídas pela prática, existem quase independentemente dela. Razão pela qual as relações sociais do capitalismo não podem ser captadas adequadamente pelas relações de classe.

Essas relações sociais devem ser apreendidas como formas de mediação social que são expressas pelas categorias de mercadoria, valor e capital. Categorias que, por sua vez, estruturam e são reestruturadas por estas relações. Nesse sentido, Postone $(2004$, p. $60 ; 61)$ conclui que

a lógica do capital não é uma manifestação ilusória das relações de classe subjacentes, mas é uma forma social de dominação inseparável das formas/relações sociais características do capitalismo. Uma lógica da história e formas alienadas de relações sociais são intrinsecamente relacionadas.

Em conformidade com sua argumentação, Postone (2004, p. 61) mantém que Marx - por se referir à determinação conceitual do espírito de Hegel -, ao tratar da categoria de capital, "sugere que a noção de Hegel de história como um desdobramento dialético direcional é válida, mas somente para a era capitalista". Só no capitalismo teríamos uma substância (trabalho abstrato) social qualitativamente homogênea e que garante a existência do capitalismo como totalidade social. As outras sociedades, onde não domina o modo de produção capitalista, possuem relações sociais que não são qualitativamente homogêneas. Em consequência, "não podem ser totalizadas - elas não podem ser apreendidas pelo conceito de 'substância', não podem ser desdobradas a partir de um princípio estruturante, singular, e não apresentam uma lógica histórica necessária, imanente." (POSTONE, 2004, p. 61).

As formas que antecedem o modo de produção capitalista, apesar de não terem um princípio estruturante e uma lógica temporal newtoniana, são totalidades com legalidades específicas. A lógica da história, no modo de produção capitalista, é a da história do capital. Nesse caso, tem-se uma forma logicista de apresentação da história que não é histórica. É um modo de operar que na aparência se põe como histórico, mas em sua essência é lógico, mera passagem do tempo.

Para Postone Marx realiza, em O capital, uma reinterpretação crítica do postulado hegeliano do espírito automovente, que se põe no mundo enquanto sujeito-objeto idêntico. Na leitura sugerida por ele, sendo o sujeito não o Geist, mas o capital, conclui-se que as relações capitalistas não são extrínsecas ao Sujeito e tampouco impedem a sua plena realização. Na verdade, não há impedimento para sua plena realização. Significa dizer 
que Marx não postula ou presume um sujeito meta-histórico, por exemplo, o proletariado, que irá realizar a si mesmo na sociedade emancipada. Ao contrário, com Marx teríamos as bases para a crítica de tal postulado. Portanto, para Postone, sua proposta interpretativa é distinta das concepções teóricas para as quais a totalidade social constituída pelo trabalho seria o ponto de vista da crítica ao capitalismo e que, no socialismo, ocorreria sua realização plena.

Em O capital, pelo contrário, essa totalidade e o trabalho a ela associado são o objeto da crítica. Evidentemente, nesse caso, a conclusão lógica é de que a negação do mundo do capital exige a abolição desse sujeito (o capital), de sua contraparte necessária (o trabalho proletário) e da totalidade por ambos constituída, e não a realização plena trabalho proletário (POSTONE, 2004).

Após argumentar que Marx fundamenta a lógica histórica desdobrada em $O$ capital no duplo caráter da mercadoria e, portanto, na formacapital, Postone (2004, p. 60-61; 2014, p. 333s.) retoma o valor como forma temporalmente determinada de riqueza e reafirma que ele possui em si uma orientação para o aumento da produtividade - marca da produção capitalista.

Muito embora, como se sabe, o valor seja mensurado pelo tempo de trabalho socialmente necessário, os aumentos de produtividade da sociedade como um todo implicam um enorme crescimento da produção da riqueza na forma de mercadorias, mas não redundam em um aumento do valor. O efeito do aumento da produtividade sobre o valor consiste na redução da unidade de tempo que serve de referência, no caso, a hora de trabalho social (tempo por unidade de mercadoria). Em consequência, com o aumento da produtividade e a redução do tempo gasto para a produção das mercadorias necessárias para a manutenção e reprodução da força de trabalho, o nível básico para a mensuração do valor se modifica continuamente, de modo que, na mesma hora temporalmente tratada, obtém-se uma quantidade cada vez maior de mercadorias. Em outras palavras, a medida continua sendo a hora, mas o aumento da produtividade, a elevação da força produtiva do trabalho permite que em meia hora, por exemplo, produzam-se tantas ou mais mercadorias do que antes, em uma hora. De tal maneira que a sociedade passa a ter a cada vez um novo nível básico de referência para a mensuração do valor. A essa dinâmica peculiar do capital (de transformação e reconstituição da determinação temporal abstrata do valor) que se impõe à totalidade da formação social capitalista Postone chama de treadmilleffect.

Segundo Postone, quando Marx passa a tratar da categoria de mais-valor relativo, a exposição assume uma lógica histórica caracterizada pela aceleração temporal. Com o mais-valor relativo, o aumento da produtividade social em geral deve gerar um aumento do próprio mais-valor. 
E isso sem que haja correspondência entre o aumento da riqueza material produzida e o aumento da riqueza social na forma de valor.

Nas sociedades em que domina o modo de produção capitalista, argumenta Postone interpretando Marx (2004, p. 62-63; 2014, p. 222s.), o aumento da força produtiva do trabalho não implica a redução da necessidade geral por gasto de tempo de trabalho. Tal redução seria possível, por exemplo, em uma formação social em que a riqueza material fosse a forma específica de riqueza. No capitalismo ocorre o oposto: a necessidade em questão é permanentemente reconstituída. O trabalho como meio necessário para a reprodução individual e o gasto de tempo de trabalho para a sociedade como um todo permanecem fundamentais para a sociedade como um todo independentemente do nível de produtividade.

Efeito que se explica, como já se viu, pelo fato de que o trabalho sob a lógica do capital tem um duplo caráter: é ao mesmo tempo trabalho concreto e trabalho abstrato. Sendo o capital valor em expansão e o valor, trabalho abstrato, este último deve permanecer como o aspecto central e fundamental para a continuidade do processo de valorização do valor.

Postone (2004, p. 63; 2014, p. 336s, 344s.) conclui que há uma dinâmica histórica de transformação e reconstituição direcional, mas não linear. De tal modo que "história no capitalismo não é uma simples história do progresso - técnico ou de outro tipo." (POSTONE, 2004, p. 63). Na verdade, ela tem um duplo aspecto. Por um lado, a dialética do valor e do valor de uso acelera as transformações da vida social a partir dos avanços do progresso técnico, que incide sobre a divisão do trabalho gerando aumentos de produtividade. Por outro, "a dinâmica histórica do capitalismo reconstitui suas próprias condições fundamentais como uma característica imutável da vida social." (POSTONE, 2004, p. 63). Em outros termos, a mediação social do valor é sempre efetivada pelo trabalho independentemente do nível de produtividade alcançado.

A dinâmica histórica do capital, engendrada pela mediação social do valor, se põe para além da necessidade do valor e do trabalho proletário e, ao mesmo tempo, reconstitui essas necessidades como condição de vida e de reprodução do capitalismo. Tal dinâmica gera continuamente o "novo", enquanto regenera o "mesmo". Não obstante dê origem à possibilidade de outra organização da vida social, essa dinâmica impede a efetivação de tal possibilidade (POSTONE, 2004, p. 63; 2014, p. 344s).

Desse modo, o autor enfatiza que essa dinâmica produz uma forma de dominação exclusiva do capitalismo e que só pode ser compreendida levando-se em consideração que a "dualidade instável das formas mercadoria e capital acarreta uma interação dialética entre valor e valor-de-uso que subentende uma dinâmica histórica complexa que é o coração do mundo moderno." (POSTONE, 2004, p. 63; 64). Na prática, para Postone (2004, p. 64), isto significa o 
abandono das hipóteses trans-históricas de que a história humana em geral apresenta uma dinâmica, para demonstrar que uma dinâmica histórica é uma característica historicamente específica do capitalismo. Esta dinâmica dialética que não pode ser capturada nem em termos do Estado nem da sociedade civil [...].

Desdobrando seu raciocínio, o autor argumenta que a dinâmica histórica do capitalismo "não é simplesmente uma sucessão linear de presentes, mas envolve uma dialética complexa de duas formas de constituição do tempo." (POSTONE, 2004, p. 64). De um lado, acumulação de tempo passado (trabalho morto) que reduz a necessidade de trabalho presente (valor); de outro, a forma de tempo que é "concreta, heterogênea e direcional": o tempo histórico.

Tempo histórico e tempo abstrato são inter-relacionados e são formas de dominação. Os indivíduos constituem o tempo histórico, porém não dispõem dele. O tempo histórico associa-se à produção de valores de uso, ao aumento da produtividade; contudo, não altera o tempo abstrato. Porém, como indicado acima, modifica o padrão de valores de uso produzidos na hora de trabalho abstrata.

O aumento da produtividade implica o aumento da quantidade de valores de uso produzidos na mesma hora de trabalho, de modo que a soma dos valores de uso contém a mesma quantidade de valor. Todavia, cada valor de uso individualmente possui menos valor do que na situação anterior. $\mathrm{O}$ aumento da produtividade da força de trabalho potencialmente assinala a possibilidade da libertação do ser humano da obrigatoriedade do trabalho, mas a necessidade da produção de valor e mais-valor, de capital, reforça a necessidade do trabalho vivo. Em outras palavras: o trabalho passado, morto, objetivado nos meios de produção e que está manifesto no tempo histórico, reforça a necessidade da constante transformação da produção no tempo presente. Produzindo, por esse caminho, a dominação do tempo abstrato no presente. Tal movimento é decorrente da necessidade de reconstituição da condição fundamental do capital: a mediação social através das mercadorias produzidas pelo trabalho humano.

O autor compreende criticamente a existência de uma dinâmica histórica no capitalismo "como uma forma de heteronomia relacionada com a dominação do tempo abstrato, para a acumulação do passado de uma forma que reforça o presente". (POSTONE, 2004, p. 64). Na estrutura proposta por Postone, essa dinâmica histórica não é vista positivamente, ela não é "o motor positivo da vida social humana" (ibid.). Aqui a acumulação do passado se apresenta em uma tensão crescente com a necessidade do presente - por um lado, a necessidade da produção de valor pelo trabalho vivo que também reanima o trabalho passado, morto, contido nos meios de produção e, por outro, o aumento da produtividade possibilitado pelo desenvolvimento técnico dos meios de produção que reduz a necessidade da utilização de trabalho vivo. O futuro é tornado possível pela apropriação 
do passado, do trabalho já realizado, objetivado, e reatualiza a dominação abstrata dos produtos do trabalho sobre os produtores.

Tomando a análise de Marx dos processos de produção e de valorização enquanto momentos constitutivos do processo de produção capitalista, a abordagem de Postone $(2004$, p. 65 ; 66) não apreende o processo de produção capitalista como um processo meramente técnico que, ainda que faculte o aumento da sociabilidade, é ao mesmo tempo apropriado pelos capitalistas para o atendimento de seus objetivos particulares. Referindo-se à diferença que Marx estabelece entre a subsunção formal e real do trabalho ao capital, Postone assinala que na subsunção real o processo de valorização molda a própria natureza do processo de trabalho; com ela a produção torna-se intrinsecamente capitalista.

Em consequência, afirma ele, a produção de uma sociedade póscapitalista exige a transformação das estruturas de produção e da própria organização da produção herdadas do capitalismo. Por conseguinte, não é possível conceber a produção de uma sociedade pós-capitalista com o mesmo padrão da produção capitalista. O desafio seria modificar as formas da própria produção e não operar simples mudanças nas formas jurídicas de propriedade ou nas formas de distribuição da produção.

Considerando a categoria de subsunção real do trabalho ao capital, Postone (2004, p. 66) propõe que, num nível alto de abstração, ela está "fundamentada no imperativo dual do capital - um direcionamento para o contínuo aumento da produtividade e a reconstituição estrutural da necessidade de gasto direto de força de trabalho no nível social como um todo". Este par de opostos seria capaz de explicar em boa parte a forma material do pleno desenvolvimento da produção capitalista. Pois o aumento de produtividade, como imperativo do capital, é obtido mediante o uso de tecnologias cada vez mais sofisticadas e que implicam a economia de trabalho presente em relação ao trabalho passado. O que por si só coloca a possibilidade da redução da jornada de trabalho e da reorganização social do próprio processo de trabalho.

Entretanto, a lógica que estrutura a produção capitalista obstrui a realização dessas tendências. "Não há liberação da maioria dos trabalhadores dos trabalhos parciais e fragmentados e, [portanto], a jornada de trabalho não é reduzida no nível social total, mas é distribuída desigualmente, até mesmo aumentada para muitos." (POSTONE, 2004, p. 66). Lógica que permite afirmar que a produção capitalista não pode ser compreendida unicamente do ponto de vista tecnológico. Em lugar disso, requer a consideração das mediações sociais postas pelas categorias mercadoria e capital.

Para o autor, a teoria crítica de Marx põe no centro da dinâmica capitalista não a contradição entre produção e distribuição ou entre propriedade privada dos meios de produção e mercado, e tampouco a luta de classes (POSTONE, 2004). O cerne da dinâmica, na verdade, é o duplo caráter de formas sociais constitutivas dessa formação: valor, valor de uso e 
tempo socialmente constituído. Tais formas sociais postas pelo trabalho no capitalismo é que estruturam a luta de classes que, logicamente, são uma parte integrante da dinâmica do capitalismo, mas não o seu fundamento. (Postone, 2004, p. 66-67; 2014, p. 348-349).Em outras palavras, as relações sociais de dominação no capitalismo acontecem através do trabalho. Elas são portadoras de um aspecto formal e abstrato, sendo portanto duais, e se caracterizam pela oposição de uma dimensão abstrata geral e homogênea e outra concreta e particular.

Postone (2004, p. $67 ; 2014$, p. 376) assinala que, com o advento da grande indústria, "as forças produtivas sociais do trabalho concreto apropriadas pelo capital não são mais as dos produtores imediatos". As forças produtivas sociais do trabalho concreto não existem primeiro como "forças dos trabalhadores que são tomadas deles. Antes, elas são forças produtivas socialmente gerais. A condição para o seu vir a ser historicamente é precisamente que elas sejam constituídas numa forma alienada, separada e oposta aos produtores imediatos".

Portanto, a categoria marxiana de capital tem por objetivo capturar esta forma alienada acima assinalada. Logo, capital, segundo Postone (2004, p. $67 ; 68)$,

é a forma real da existência de capacidade da espécie [humana] [species capacity] que são historicamente constituídas numa forma alienada. Capital, então, é a forma alienada de ambas as dimensões do trabalho social no capitalismo. Por um lado, ele confronta os indivíduos como algo estranho, uma Outra totalidade. Por outro, as capacidades da espécie historicamente constituídas na forma de capital abrem a possibilidade histórica de uma forma de produção social que não se basearia na produção de excedente mediante o gasto de trabalho humano vivo na produção, ou seja, no trabalho de uma classe produtora de excedente.

Sob essa ótica, Postone (2014, p. 214-215) afirma que o capital não existe como uma totalidade unitária, de tal forma que a conhecida contradição dialética entre forças produtivas e relações de produção não dizem respeito a uma contradição

entre 'relações' que são intrinsecamente capitalistas (tais como mercado e propriedade privada) e 'forças' que significativamente são extrínsecas ao capital. Ao contrário, tal contradição dialética se dá entre as duas dimensões do capital. Como uma totalidade contraditória, capital é o gerador do complexo dinâmico histórico [...], que põe a possibilidade de sua própria superação.

Por isso, prossegue o autor, a contradição estrutural do capitalismo não é entre a esfera da distribuição (mercado e propriedade privada) e a esfera da produção, entre as relações de propriedade que existem no capi- 
talismo e a produção industrial que é produto da lógica do capital. "Em lugar disso, ela emerge como uma contradição entre formas existentes de crescimento e produção e o que poderia ser se as relações sociais não fossem mediadas numa forma abstrata pelo trabalho." (POSTONE, 2004, p. 68).

Fazendo um contraponto entre a estrutura teórica por ele proposta com o que denomina de marxismo tradicional, Postone (2004, p. 69; 2014, p. 458) assinala que no marxismo tradicional o trabalho é tomado como uma categoria "trans-histórica e constitui um ponto de vista quase-ontológico da crítica do capitalismo." ${ }^{10} \mathrm{Em}$ sua estrutura interpretativa, pelo contrário, o trabalho é o objeto da crítica. No marxismo tradicional "as formas categoriais do capital velam as 'reais' relações sociais do capitalismo". Para ele, por sua vez, estas categorias "são aquelas relações sociais". Ou seja, as estruturas imateriais de mediação capturadas por Marx não escondem as relações sociais reais do capitalismo, elas "são as relações fundamentais [...] e constituem o sujeito".

Em suma, o chamado marxismo tradicional procura entender o capitalismo partindo das relações entre as classes sociais, sendo estas, por sua vez, estruturadas pelo mercado e pelas relações de propriedade. Justamente por isso procura capturar as formas de dominação do capitalismo partindo das noções de dominação de classe e exploração e "formulando uma crítica normativa e histórica do capitalismo do ponto de vista do trabalho e da produção (entendidos em termos trans-históricos da interação dos homens com a natureza material)." (POSTONE, 2004, p. 70). Já a formulação de Postone procura demonstrar que a análise marxiana do trabalho no capitalismo tem por objetivo desvendar a dominação abstrata que não só estrutura a produção como gera a dinâmica específica da sociedade capitalista.

A leitura de Postone busca ultrapassar a crítica às formas burguesas de distribuição que focam no mercado e na propriedade privada. Visa tratar da indústria como indústria constituída pela lógica do capital. Por isso, toma a classe trabalhadora como o elemento básico do capitalismo e não como encarnação de sua negação. Logo, o socialismo não envolve a realização do trabalho e da produção industrial tal como herdados do capitalismo, mas exige a "abolição do proletariado e da organização da produção baseada no trabalho proletário, tanto quanto do sistema dinâmico de compulsão abstrata constituído pelo trabalho enquanto atividade socialmente mediadora." (POSTONE, 2004, p. 70). O socialismo exige, então, uma transformação geral das estruturas de trabalho e do tempo. Por tudo isso, Postone sente-se justificado ao propor que Marx elabora uma crítica do trabalho no capitalismo e não uma crítica do capitalismo do ponto de vista do trabalho.

${ }^{10}$ Ver nota 9 sobre o equívoco do autor em identificar ontologia com postulações metafísicas. 
Como a construção de Postone afasta a centralidade do trabalho tanto da esfera teórica quanto da política, ele se obriga a adiantar novos caminhos para a superação do capital e para a abolição do trabalho proletário. Tais caminhos passariam pela emergência histórica das subjetividades e do autoentendimento ou autorreconhecimento do pós-proletariado. ${ }^{11}$

Eles abrem a possibilidade para uma teoria que possa refletir historicamente nos novos movimentos sociais das últimas décadas do século $X X$, cujas demandas e necessidades expressas têm muito pouco a ver com o capitalismo como tradicionalmente é entendido [...]. [Essa teoria] deveria ser capaz de tratar de tais movimentos, explicando historicamente sua emer-gência e a natureza das subjetividades expressas. (POSTONE, 2004, p. 71).

\section{Considerações finais}

H.G. Backhaus, autor da epígrafe do presente artigo, é um dos teóricos que deram origem à chamada "Nova Leitura de Marx" que inspira autores como M. Postone, M. Heinrich, R. Kurz entre outros. Sem sabê-lo ou pretendê-lo, Backhaus afirma na epígrafe a natureza ontológica da crítica de Marx ao defender enfaticamente a ideia de que a "crítica de las categorías económicas de Marx trasciende el dominio de la economía como disciplina especializada". De fato, considerando que toda ciência subentende uma ontologia ou, caso se queira, que é impossível falar de "lugar nenhum" (ontológico), se a crítica de Marx fosse exercitada no interior do domínio da economia como disciplina especializada, ela não poderia de modo algum ser, como ele próprio reivindica, crítica das concepções geradas e requeridas pelas relações sociais da formação capitalista e, portanto, crítica das próprias relações.

A crítica praticada na disciplina especializada é crítica que não abrange nem pode abranger a ontologia em que a disciplina está fundada. ${ }^{12}$ É crítica que gira em torno das maneiras de "melhor" administrar a sociedade existente, prática que expressa a natureza instrumental da ciência. Precisamente por essa razão, Marx não procura estabelecer uma interlocução com a ciência econômica, quaisquer que sejam suas correntes; ao contrário, ela é o objeto da crítica.

De maneira similar, e também sem se dar conta de que lida com questões ontológicas, Postone chama a atenção para a diferença entre economia política crítica e crítica da economia. A primeira é positiva, crítica do que existe com base no que existe. A crítica da economia política de Marx é negativa: é crítica do que existe com base no que poderia ser, crítica que, portanto, sem desconsiderar os constrangimentos e condições

${ }^{11}$ Vide Postone, 2014, p. 429s. 
do presente, investiga os futuros que sua historicidade necessariamente encerra (POSTONE, 2014, p. 84).

A crítica positiva pressupõe, ao menos de forma tácita, uma ontologia em que a configuração presente do mundo é inalterável pela prática dos sujeitos; a crítica negativa, por sua vez, está fundada em uma ontologia em que o mundo social, por ser reproduzido e transformado pela práxis humano-social, é figurado em sua historicidade específica e no qual, conforme foi possível mostrar com Lukács, a subjetividade cumpre um papel central. Em síntese, mesmo sem reconhecê-lo ou mesmo admitilo, Backhaus e Postone corroboram a análise de Lukács, de modo que as considerações acima permitem reafirmar que a crítica marxiana se instaura como crítica ontológica.

Como foi visto na segunda seção, a análise do complexo do trabaIho realizada por Lukács esclareceu, delimitando-a concretamente, a historicidade específica do ser social, porquanto ele, em primeiro lugar pelo trabalho, produz as condições materiais de sua vida. A autocriação daí resultante envolve sempre a emergência do novo, de modo que a Lukács parece razoável assegurar que o típico no ser social é a reprodução ampliada, posta em movimento pelo agir teleológico. Tal reprodução se manifesta na complexificação e diferenciação da sociedade, na emergência de novos complexos, processo que tem por pressuposto o aumento da produtividade do trabalho social, já enfatizado anteriormente.

$\mathrm{Na}$ verdade, contra as concepções que negam a possibilidade de se apreender as legalidades do mundo social, Lukács sustenta que, no que diz respeito à produtividade do trabalho, é possível inferir que o seu aumento constitui uma legalidade tendencial própria do ser social, cujo desenvolvimento - recuo progressivo das barreiras naturais - tem por pressuposto justamente a crescente produtividade do trabalho.

Essa dinâmica peculiar ao ser social, essa capacidade do trabalho social de produzir suas condições de maneira ampliada e, ao mesmo tempo, reduzir continuamente o tempo de trabalho necessário, se manifesta no capital sob a forma de mais-valor, capacidade estranhada dos sujeitos e que, em consequência, embora funcione como mecanismo que universaliza as relações sociais, plasma a primeira sociedade propriamente dita, também o faz de forma estranhada.

Viu-se com Lukács que o trabalho é decisivo na gênese do ser social e pressuposto insuprimível de seu desenvolvimento. Nessa dinâmica, naturalmente, o trabalho é fundante, uma vez que ela é condicionada pelo aumento da produtividade. Todavia, em razão de sua própria lógica, o trabalho, por definição, progressivamente deixa de ser central na constelação de complexos que compõem o ser social. A centralidade do trabalho sob o capital, por conseguinte, constitui a principal contradição do sistema, além

${ }_{12}$ Para um tratamento detalhado dessas questões, ver Duayer (2015). 
de manifestar o caráter estranhado dessa forma da produção social. Contradição e estranhamento que Marx (2011, p. 705) expõe, como se segue:

O fato de que, com o desenvolvimento das forças produtivas do trabaIho, as condições objetivas do trabalho, o trabalho objetivado, têm de crescer em relação ao trabalho vivo - trata-se, na verdade, de uma proposição tautológica, pois o que significa força produtiva do trabalho crescente senão que se requer menos trabalho imediato para criar um produto maior e que, portanto, a riqueza social se expressa cada vez mais nas condições de trabalho criadas pelo próprio trabalho -, tal fato, do ponto de vista do capital, não se apresenta de tal maneira que um dos momentos da atividade social - o trabalho objetivo - devém corpo cada vez mais poderoso do outro momento, do trabalho subjetivo, vivo, mas de tal maneira que - e isso é importante para o trabaIho assalariado - as condições objetivas do trabalho assumem uma autonomia cada vez mais colossal... em relação ao trabalho vivo.

Postone certamente é o autor que mais contribuiu para esclarecer o fato de que a centralidade do trabalho é exclusiva do capitalismo. Sem dúvida, deve-se a ele a ênfase na função mediadora do trabalho e, em consequência, como categoria constituinte das relações sociais da sociedade moderna: "[...] a teoria de Marx propõe que o traço distintivo que caracteriza o capitalismo é precisamente o fato de que suas relações sociais básicas serem constituídas pelo trabalho." (POSTONE, 2014, p. 20). Tal interpretação da teoria de Marx, sublinha ele, distingue-se radicalmente das interpretações correntes na tradição marxista, que, por estarem baseadas na noção de que o trabalho é central em todas as sociedades, imaginam que a crítica de Marx é crítica do ponto de vista do trabalho. Muito pelo contrário, insiste ele, a crítica de Marx, pela razão apontada, é crítica do trabalho no capitalismo, de sua centralidade no capitalismo, portanto.

Se o trabalho é categoria mediadora que constitui a sociedade, as relações sociais de dominação no capitalismo, argumenta Postone, se dão através do trabalho. O trabalho proletário é, por conseguinte, a contraparte necessária do capital, e o metabolismo do capital impõe um constante aumento da produtividade do trabalho que, em lugar de livrar os seres humanos da coerção do trabalho, reconstitui continuamente a necessidade do trabalho vivo de reavivar o trabalho morto, objetivado, contido nos meios de produção como capital.

Os ganhos de produtividade do trabalho que, num primeiro momento, reduzem o valor contido em cada unidade de mercadoria produzida, num segundo momento, com a transformação dessa nova forma de produzir em padrão social, reduzem o tempo de trabalho socialmente necessário para a produção das mercadorias. Esses ganhos de produtividade, só podem ser contabilizados através do tempo lógico. Tal movimento no mundo do capital instaura, como assinala Postone, uma dominação do tempo sobre os seres humanos. 


\section{Referências}

AHMAD, A. Reconciling Derrida: "Spectres of Marx" and deconstructive politics. New Left Review, n. 208. 1994.

ANDERSON, P. Arguments within english marxism. London: NLB/Verso. 1980.

ARAUJO, P.H.F. Superação do capitalismo a partir da lógica humano-societária do trabalho? Postone, Lukács e Chasin se encontram. Verinotio, n. 13, anoVII, abr.2011.

DERRIDA, J. Spectres of Marx. New Left Review, n. 203.1994.

DUAYER, M. Desencanto revolucionário, ininteligibilidade da história e apostasia de esquerda: E.P. Thompson sobre L. Kolakowski. Crítica Marxista, n. 22, maio de 2006.

. J.L. Borges, filosofia da ciência e crítica ontológica: verdade e emancipação. Margem Esquerda, n. 24, jun.2015.

LUKÁCS, G. Para um a ontologia do ser social I. São Paulo: Boitempo.2012. LUKÁCS, G. Para uma ontologia do ser social II. São Paulo: Boitempo.2013. MARX, K. Grundrisse. Manuscritos econômicos de 1857-1858, esboços da crítica da economia política. São Paulo: Boitempo.2011.

MURTHY, V. Reconfiguring historical time: Moishe Postone's interpretation of Marx. In: POSTONE, M.; MURTHY, V.; KOBAYASHI, Y. (org.). History and heteronomy: critical essays. Tokyo: UTCP. 2009.

OLDRINI, G. Em busca das raízes da ontologia (marxista) de Lukács. In: LUKÁCS, G. Para uma ontologia do ser social II. São Paulo: Boitempo.2013. POSTONE, M. Critique and historical transformation. Historical materialism, v. 12-3.2004.

. Tempo, trabalho e dominação social. São Paulo: Boitempo. 2014.

POSTONE, M.; MURTHY, V.; KOBAYASHI, Y. (org.). History and heteronomy: critical essays. Tokyo: UTCP. 2009.

TERTULIAN, N. O grande projeto da ética. Ad Hominen, São Paulo, n. 1.1999. . Sobre o método onto-genético em filosofia. Perspectiva, Florianópolis, v. 27, n. 2, jul./dez. 2009.

THOMPSON, E.P. An open letter to Leszek Kolakowski. In: THOMPSON, E.P. The poverty of theory and other essays. London: Merlin Press.1978.

Recebido em 12 de junho de 2015

Aprovado para publicação em 20 de junho de 2015. 